Revista Iberoamericana, Vol. LXXVI, Núm. 232-233, Julio-Diciembre 2010, 975-980

\title{
ENTREVISTA A MARCELO BIRMAJER
}

POR

Marcela Pardes

Temple University

Marcelo Birmajer es uno de los escritores argentinos jóvenes más prolíficos y versátiles. Algunos de sus libros publicados incluyen las colecciones de cuentos Fábulas salvajes (1996), El fuego más alto (1997), Ser humano y otras desgracias (1997), Historias de hombres casados (1999), Nuevas historias de hombres casados (2001), y Últimas historias de hombres casados (2004); y las novelas Un crimen secundario (1992), Un veneno saludable (1995), No tan distinto (1999), y Tres mosqueteros (2001). En colecciones juveniles ha publicado varias novelas y colecciones de cuentos, entre otros, El alma al diablo (1994), El abogado del marciano (1997), Mitos y recuerdos (1999), y No es la mariposa negra (2000). Traducido a varios idiomas, fue honrado con el premio Konex 2004 como uno de los cinco mejores escritores de la década 19942004 en el rubro Literatura Juvenil. También ha incursionado en el teatro con Cuatro vientos y el saxo mágico (1994), y en el cine como coautor del guión de la película El abrazo partido, ganadora del Oso de Plata en Berlín 2004 y nominada al Oscar por la Academia Argentina de Cine. Ha escrito en varios periódicos y revistas de Argentina ( $L a$ Nación, Clarín, Página/12), España (ABC, El País, El Mundo) y Chile (El Mercurio). En su último libro, El Once (2006), combina ensayo, cuento e historia para ofrecernos una imagen personal de su barrio favorito.

Me encontré con Marcelo Birmajer una mañana de invierno del 2007 en su estudio del barrio del Once en Buenos Aires. Entre mates y libros tuvimos esta conversación.

Marcela Pardes: Tu obra literaria es muy amplia y variada. Has escrito literatura juvenil, cuento, novela, ensayo, teatro, incluso guión cinematográfico.¿Hay algún motivo por el que has incursionado en tantos géneros diferentes? ¿Es el producto de un proceso de evolución o de experimentación? ¿Qué te atrae/interesa más en cada uno?

Marcelo Birmajer: Los cuentos y las novelas son fruto de mi vocación. Escribo cuentos y novelas porque sí. Los escribiría me pagaran o no, me publicaran o no. Nunca podría dejar de escribir. Empecé a escribir sin decidirlo y creo que nunca decidiría dejar de escribir. Los guiones cinematográficos, los artículos periodísticos, eso está más en el rubro del oficio, es decir, yo vivo de lo que escribo. Muchas veces tengo que escribir 
cosas por encargo, y son trabajos que estoy muy feliz de haber hecho, pero que si no me los hubieran encargado no los hubiera hecho. No voy a escribir un guión cinematográfico vocacionalmente. Me tienen que pagar para que lo quiera escribir, pero, gracias a que me lo pagan he escrito obras que me dejan muy conforme, y que son idénticas en su calidad y en la pasión que pongo a las que escribo por vocación.

MP: Tu escritura se caracteriza por su sencillez y cotidianidad, pero al mismo tiempo expresa con profundidad las emociones y la naturaleza humanas. ¿ Es esto el resultado de un proceso escritural consciente? ¿Cuál es tu acercamiento al proceso de escritura?

MB: La combinación entre la simplicidad del texto y la complejidad de los conflictos que trato no es algo que yo me proponga, es algo que sale naturalmente en mi escritura. Ahora, sí soy consciente de la necesidad de escribir una novela o de escribir cuentos. Muchas veces soy atacado por la necesidad compulsiva de escribir. Pero, cuando no escribo no me lo tomo a la ligera, no siento ese tiempo que pasa sin escribir como natural. Primero, porque escribir le da sentido a mi vida, y en segundo lugar, porque no hago otra cosa que escribir. De modo que cuando no escribo no hago nada, y siempre me siento como viviendo en un kibutz, en el sentido que me levanto en la mañana y me tengo que poner a trabajar. No concibo la vida sin trabajar. Si yo no trabajo alguien está trabajando por mí, y eso no lo puedo aceptar.

MP: El lector puede percibir en tu narrativa tu placer por escuchar y narrar historias. ¿Cuáles son las historias que más te atraen? ¿Por qué?

MB: Me atraen muy distintos tipos de historias, pero las podría englobar en grandes temas. El amor, sin lugar a dudas. El amor como relación de poder, el amor como obsesión. Si hay amor romántico tiene que estar cruzado por cierta perversión, por cierta malicia para que a mí me atraiga la historia. Me atraen las historias de guerra, específicamente, la Segunda Guerra Mundial y la guerra del Medio Oriente, las guerras de los judíos. En general, las guerras de los judíos me atraen mucho, las guerras que narró Flavio Josefo, la guerra de Israel, los Macabeos. Esa temática me resulta muy atractiva. Tengo mi biblioteca llena de esas historias, tanto en sus versiones noveladas como históricas. Me gusta mucho la sorpresa. El género fantástico y lo que tiene de sorpresivo. Que me cuenten una idea que a mí no se me había ocurrido antes. Eso me entretiene y me invita mucho a pensar. Esos son, a grandes rasgos, los tres géneros o temas que a mí me cautivan. El amor, la guerra, específicamente aquella que está vinculada a la historia judía, o más, por ejemplo, Churchill también me fascina, Roosevelt, las novelas con ellos como personajes me resultan atractivas. En tercer lugar, lo fantástico, que haya un prodigio o una alteración de la realidad que a mí nunca se me hubiera ocurrido.

MP: Con respecto al tema de los escritores que consideras seminales en tu formación literaria hablás en El Once del ABC de la literatura argentina: Arlt, Borges, Cortázar, Adolfo Bioy Casares. En algunas entrevistas has mencionado a Somerset Maugham, Philip Roth, y en particular, Isaac Bashevis Singer. ¿De qué manera han influido estos escritores en tu obra?

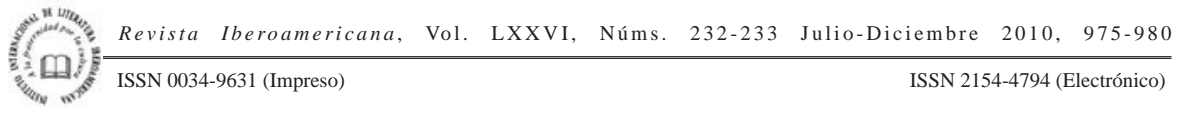


MB: Arlt, Borges y Cortázar, con todas sus diferencias, en un modo de narrar lo argentino. Una manera de acercarme a la Argentina evadiendo la solemnidad y el falso nacionalismo. Una Argentina que me incluye y a la que yo incluyo en mis textos. Borges, en particular, sus posiciones políticas, su anti-nazismo, en un momento en los cuarenta donde la inteligencia nacionalista argentina era pro-nazi, en el mejor de los casos, neutral, lo cual para mí resulta inaceptable. Borges iluminó a los argentinos con su anti-nazismo declarado y claro. También fue siempre un defensor de la pluralidad y un luchador contra el antisemitismo, con muy distintos tipos de artículos, todos ellos preclaros y valientes. Por eso, que se haya equivocado tal vez en algún momento de la historia argentina me parece menor, en comparación con los aciertos que tuvo cuando toda la inteligencia nacionalista se equivocó de la peor manera. Por eso defiendo tanto a Borges, un hombre inteligente, valiente, el más inteligente de todos nosotros. Adolfo Bioy Casares por su sencillez, por la naturalidad con la que escribió las mejores historias de amor de Argentina, y algunos de los mejores cuentos fantásticos también, que son dos de los temas que a mí más me apasionan. Somerset Maugham por su malicia, por su cinismo, por su inteligencia brutal para describir el amor entre las personas. Para mí, él es el mejor escritor de todos. Todos los demás en distintas cosas tal vez son mejores que Somerset Maugham, pero Somerset Maugham es literatura pura. No tiene ninguna otra ventaja más que ser el mejor escritor. Con todos los demás, de algún modo me siento identificado por otros motivos. Ni que hablar el caso de Singer, que es mi maestro y mi horizonte literario. Realmente, uno con Singer ya se puede quedar tranquilo porque ya alguien escribió todo lo que uno hubiera necesitado escribir. Él lo dijo todo. Pero no es sólo un escritor. A diferencia de Somerset Maugham, Singer es mucho más. Es un faro filosófico, identitario, de fe, es un modo de acercarse a Dios, de mirar el mundo. Singer es el más grande. No como persona, como escritor, como espíritu. Como hombre es igual a todos nosotros.

MP: De los escritores de tu generación, ¿hay algunos con los que sentís mayor afinidad (por los temas, las ideas, los intereses, etc.)? ¿Te considerás parte de un grupo de escritores (ya sea a nivel nacional o internacional)?

MB: Ahí me faltó uno que podría incluir ahora, aunque no es de mi generación, con el cual me siento muy cercano, que es Philip Roth. Yo lo considero casi generacional conmigo. Me siento personalmente mucho más cerca de Roth que de Singer. Roth es nacido en la diáspora, la diáspora occidental quiero decir. Singer nació en lo que fue el falso estado judío, que era Europa Oriental. Era el lugar donde nacían los judíos. Nosotros hemos nacido en diásporas amables, con todos los problemas. Obviamente, Roth nació en la diáspora más amable del mundo, incluso más amable que el Estado de Israel. No más auténtica ni más cómoda, pero amable. O sea, un judío norteamericano está más seguro que un judío israelí. Eso es innegable. Si no existiera el Estado de Israel tal vez no estaría seguro un judío norteamericano, pero existiendo Israel, está más seguro un judío norteamericano que un judío israelí. Entonces ahí yo me siento cercano a Roth.

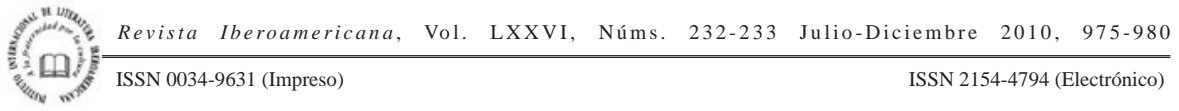


Y Roth también me influyó mucho en el modo de tratar el sexo en Tres mosqueteros. Me soltó mucho, me liberó de algún modo. El lamento de Portnoy, aunque no me gustó como libro, sí me invitó a volar más con la imaginación, a soltarme. Se lo tengo que reconocer. En cambio, Pastoral americana me pareció un libro extraordinario desde cualquier punto de vista. Me casé con un comunista también. Y El teatro de Sabbath y Operación Shylock son el corpus de su obra. Son sus obras maestras. Pero volviendo a Argentina, yo creo que hay dos escritores con los que me siento identificado, que son Guillermo Martínez y Pablo De Santis. Los dos tienen como principal virtud centrarse en narrar bien una buena historia. Son escritores muy elegantes, mucho más que yo en cuanto a elegantes, y defensores de la narrativa clásica y tradicional. Yo me siento cómodo con ellos. Somos absolutamente distintos. Nos parecemos en lo distintos que somos y tenemos un modo similar de encarar la literatura.

MP: Hablemos un poco del humor en tu literatura. En una entrevista en Rosario dijiste que "el humor es para mí uno de los más elevados métodos de llamar la atención de Dios: hacer reír a las personas, cosa que él nunca intenta.” ¿Cómo trabajas el humor en tus historias? ¿Cómo lo incorporas?

MB: El humor aparece casi tan naturalmente como las ganas de narrar. Yo creo que no podría vivir sin humor. No me pasa nada grave, pero mi sentimiento con respecto a la vida es trágico. Es decir, no soy una persona que esté derramando alegría, muy por el contrario. Sí puedo derramar energía, perseverancia, pero no alegría. Entonces es como un diabético que necesita insuflarse no sé que sustancia o esa persona que le faltan glóbulos rojos, yo necesito incorporar el humor a mi vida. No que lo busque, pero naturalmente extraigo, así como se extrae el petróleo de la tierra, extraigo del aire el humor que necesito para seguir viviendo. $Y$ eso aparece en mi literatura.

MP: ¿Pensás que no es de una manera consciente?

MB: De ningún modo. Por ejemplo, tengo tres hijos. Me despierto en la mañana y es algo que odio. Prepararlos para la escuela. Me ocupo de todo eso. Y en el medio de ese caos, de ese vértigo inhumano se me ocurre un chiste. Te puedo asegurar que no lo estoy buscando bajo ningún concepto. Me sorprendo de que se me ocurra, y se me ocurre. De modo que es compulsivo. El humor aparece en mi vida. No voy yo a buscarlo. O sea, hay algo en mí que está permanentemente extrayéndolo. Pero no es consciente.

MP: Y hay que buscarlo en las historias también. Es muy sutil a veces.

MB: Sí, es muy sutil, pero siempre está.

MP: No es el humor de reírse a carcajadas. Es un poco reírse de sí mismo

MB: Exactamente. No hay tema que no pueda ser tamizado por el humor. Y si uno respeta el tema, si uno siente el dolor auténticamente, el humor nunca resulta desubicado. No en literatura, por lo menos. En la cotidianidad es otra cosa, pero no en la literatura.

MP: A nivel más personal, ¿̇podrías señalar/comentar eventos/circunstancias de tu vida personal y/o familiar que consideras importantes en tu formación/definición como escritor?

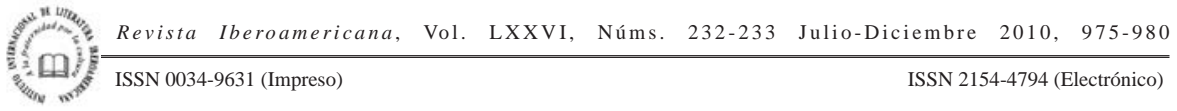


MB: Sí, cuando en Miramar mi padre nos sentaba a los tres hermanos junto a la carpa en la arena y nos contaba un capítulo de una novela, por ejemplo, Los niños del Brasil de Ira Levin. Cuando empezaba a caer el sol interrumpía, y por más que le suplicáramos no soltaba un solo dato más hasta el día siguiente, cuando el sol se comenzaba a levantar también en la playa. Eso me enseñó a mí a dosificar mis historias y manejar el suspenso con el lector. Es una enseñanza imborrable.

MP: En dos de tus novelas, El alma al diablo y No tan distinto, el Estado de Israel cumple una función muy importante. En las dos el protagonista viaja a Israel y desde allí narra su historia. ¿Has viajado a Israel? ¿Qué representa para vos y para tu literatura? ¿Cuál/cómo es tu conexión con Israel como espacio real y/o espacio mítico/literario?

MB: Yo soy judío y argentino: cien por ciento judío y cien por ciento argentino. Como judío me siento siempre relacionado con Israel. Tengo pendiente convertirme en ciudadano israelí, cosa que me gustaría mucho. No tengo una explicación clara de por qué no lo hago, pero siempre está presente en mis ideas. Mi abuelo se escapó de Polonia en el año 39. Llegó a la Argentina en un barco como polizón con la idea de traer a su familia. Nunca la pudo traer. A mí no se me escapa que de haber existido Israel antes del 39, tal vez yo hubiera podido conocer a la primera hija de mi abuelo, a sus hermanos. De modo que por motivos inexplicables y por conveniencia, soy un defensor a ultranza del Estado de Israel. Me siento directamente vinculado con ese país. En los últimos años, no, en realidad no, desde que soy un niño he viajado a Israel. No tanto como yo quisiera, pero ahora llevo nueve viajes. La primera vez que viajé fue cuando mis padres se separaron. Mi madre fue a vivir a Israel, pero duró solamente tres meses la experiencia. Yo creo que ahí me debía haber hecho ciudadano israelí. De modo que yo viví en Israel con mi madre y mis hermanos. Mi hermano menor era un bebé, yo tenía cuatro años y mi hermano mayor seis. Y fui al jardín de infantes. Fui un israelí más durante tres meses. Por supuesto, aprendí el hebreo y era un niño que iba al jardín de infantes israelí. Luego volvió mi madre y nos quedamos a vivir en la Argentina. Pero pude haber sido un sabra, casi, casi. Y desde entonces viajé ocho veces más. En los últimos años viajé mucho. Viajé en el 2001, en la peor época de los atentados, en un viaje que hicieron dirigentes judíos en solidaridad con Israel. Volví a viajar en el 2003 para escribir un guión de cine que se llama Mi primera vez acá, que todavía no se filmó. Viajé en el 2004 para una experiencia que se llamó Kol Dor, con otro grupo de dirigentes judíos. En el 2005 volví a viajar por Kol Dor. En el 2006 lamentablemente no viajé, y en octubre viajo para la presentación de mi libro en hebreo Tres mosqueteros. Es el noveno idioma al que me traducen, por primera vez el hebreo.

MP: ¿Puedes hablar un poco de Israel como espacio mitológico/literario?

MB: Me parece que la historia misma de Israel es una historia mucho más literaria que real. No parece real que los judíos, después de dos mil años, hayan dicho vamos a volver al mismo lugar desértico donde nuestros ancestros se encontraban cuando salieron de Egipto, vamos a volver con el mismo idioma que hablaban ellos aunque cada uno de

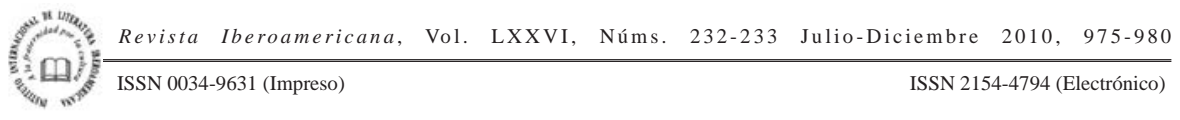


los que llega acá hable un idioma distinto, vamos a agruparnos alrededor de un mismo libro, parece un cuento de ciencia ficción. Pero fue verdad, y verdad en el sentido más profundo de la palabra verdad. Yo creo que a un escritor que pertenece a esa historia le resulta muy difícil no tenerla como referencia. Hay que hacer un gran esfuerzo para no referir esa historia. Y yo no hago ningún esfuerzo por no referir esa historia. Esa historia aparece naturalmente en mis escritos una y otra vez. Es una épica única en el siglo xx, y una de las más inspiradoras y menos salvajes, lo cual no quiere decir que sea totalmente inspiradora, ni que no tenga nada de salvaje. Es una de las más inspiradoras y menos salvajes que han ocurrido en el siglo xx. Sin duda, la más fantástica.

MP: Tu novela El alma al diablo es un Bildungsroman o novela de crecimiento, de educación. Una de las características que se le adjudican a este tipo de novelas es el carácter autobiográfico. ¿Hay componentes autobiográficos en El alma al diablo? ¿Cuáles son?

MB: El único componente autobiográfico es la relación del chico con su abuelo, que efectivamente mi abuelo vivió la misma historia que la del abuelo de Mordejai. Llegó de Polonia, hizo fortuna en la Argentina, bueno clase media alta, pero nunca pudo traer a su familia. Siguió acumulando dinero como si quisiera traerlos. Los perdió a todos en Polonia. Mi abuelo no era un hombre religioso, en lo más mínimo. Pero todos nosotros hicimos el barmitzva y yo, desde mi hijo hasta cualquier joven judío, le recomiendo que haga su barmitzva, si me piden consejo a mí. Soy un hombre más laico de lo que me gustaría. No tengo ninguna preferencia por el laicismo, pero lo soy y no reniego de eso. No tengo nada contra la ortodoxia judía, mi hermano es ortodoxo, mi hermano menor. Pero vivo como un hombre laico, para bien y para mal. No me arrepiento ni hago una apología. Así soy yo. No le exijo nada a nadie ni permito que nadie me exija nada a mí. Lo único que yo le exijo a un judío es que no se auto-odie. Uno puede o no interesarse en su identidad judía, pero lo que a mí me parece inaceptable es que se interese para atacar al Estado judío o para atacar al resto de los judíos. Eso me parece inaceptable: el auto-odio, no la indiferencia. La indiferencia la acepto, pero no el auto-odio.

$\begin{array}{llrrr}\text { Revista Iberoamericana, Vol. LXXVI, Núms. 232-233 } & \text { Julio-Diciembre } & \text { 2010, } & \text { 975-980 } \\ \text { ISSN 0034-9631 (Impreso) } & \text { ISSN 2154-4794 (Electrónico) }\end{array}$ 